\title{
La contiguiidad del tiempo en Los días de la peste de Edmundo Paz Soldán
}

\section{The contiguity of time in Los días de la peste, by Edmundo Paz Soldán}

\author{
Ellen Maria Martins de Vasconcellos ${ }^{1}$ \\ Universidad de São Paulo. São Paulo, Brasil \\ ellen.maria@usp.br \\ ORCID 0000-0001-5572-1882
}

Citar como: Martins de Vasconcellos, E. (2019). La contigüidad del tiempo en Los días de la peste, de Edmundo Paz Soldán. Desde el Sur, 11(2), pp. 61-73.

\section{RESUMEN}

En la novela Los días de la peste, del autor boliviano Edmundo Paz Soldán, una catástrofe se aproxima de la institución penitenciaria La Casona: una peste desconocida y letal, que ataca a todos, sin importar si es preso, guardia, doctor o gobernador. Sin embargo, en ningún momento la novela trata a los personajes como una sola masa informe y condenada. Son una comunidad que no tienen nada en común, excepto la inminencia del destino trágico. En este artículo, analizaremos la concepción temporal de la narrativa, que parece provenir de una interacción entre diversos tiempos en disputa, capaces de invadir y actualizarse en el presente. Contra una historia lineal de la experiencia de la peste en La Casona, la interacción de temporalidades, como un devenir, hace que el presente se configure como un lugar de resistencia, de potencia, donde las voces no son silenciadas, los separatismos no son subordinados a otros y los cuerpos no son reducidos a números. Además de los conceptos de comunidad e inmunidad, de Roberto Espósito (2017), para leer cómo interactúan e intentan sobrevivir los seres singulares delante de la inminencia

1 Ellen Maria Martins de Vasconcellos es estudiante de doctorado con un proyecto de investigación en la literatura latinoamericana contemporánea, en la Universidad de São Paulo (Brasil). En su maestría estudió la novela argentina contemporánea y su relación con los formatos televisivos y el cine. Es traductora del inglés y el español y coordinadora de idiomas en la editorial Edebé. También es autora de los libros Chacharitas \& gambuzinos y Gravidade, ambos publicados por la editorial Patuá. 
mortal, buscaremos Hartog (2015), a fin de analizar la contigüidad del pasado, presente y futuro. Es un tiempo sin tiempo, donde otros vínculos entre las vidas precarias, el territorio y la memoria pasan a ser planteados, para que la peste no los consuma, para que el propio tiempo no los comprima.

\section{PALABRAS CLAVE}

Tiempo, catástrofe, cuerpo, comunidad, literatura contemporánea

\section{ABSTRACT}

In the novel Los días de la peste, by the Bolivian author Edmundo Paz Soldán, a disaster approachs the «La Casona» prison: an unknown and deadly plague which attacks everyone, regardless of whether they are a prisoner, guard, doctor or governor. However, the novel does not depict the characters as a formless and condemned mass. They are a community of individuals who have nothing in common, save their imminent tragic fate. In this essay, we will analyze the concept of time expressed by the narrative, which appears to emerge from the interaction between different, conflicting tenses, capable of invading and modifying the present. Against the linear history of the experience of plague in "La Casona», the interaction of temporalities, like a progress of development, causes the present to be configured as a place of resistance and power, where voices are not silenced, separatisms are not subordinated to others, and bodies are not reduced to numbers. We will employ the concepts of community and immunity espoused by Roberto Espósito (2017), in order to observe how separate individuals interact and seek to survive in the face of death. And we will look to Hartog (2015) in our analysis of the contiguity of the past, present and future: time without time, where other links between the precariousness of life, territory and memory are seized upon, so that the plague cannot consume them, and time itself does not crush them.

\section{KEYWORDS}

time, disaster, body, community, contemporary literature 
La catástrofe siempre formó parte de nuestro imaginario y por eso también siempre estuvo presente en los relatos en los relatos orales y escritos, y fue objeto de representación de las muchas formas de arte desde que existe la humanidad, sea para informar, asombrar, entretener, hacer reflexionar, escenificar, reconstituir eventos históricos, proponer posibles soluciones para gestionarla, reconciliar ética y estética, etc.

Sin embargo, en los últimos años, la catástrofe, causada por fenómenos naturales, divinos o consecuencia de las acciones del hombre, también la socioeconómica o íntima, es decir, la figuración del fin, además de saturar diariamente nuestros medios de comunicación, se ha convertido en un tropo muy importante para pensar en las relaciones políticas, en los juegos de poder entre los individuos, entre identidades, discursos y cuerpos, sin disociación ya entre lo natural y lo social, la naturaleza y la cultura, la naturaleza y la Técnica (Nancy, 2014).

Como bien dijo Fredric Jameson, en el mundo en que vivimos parece ser más fácil imaginar el fin del mundo que el fin del capitalismo, y por eso la catástrofe parece ser la única salida capaz de descomponer el Estado, de desarticular el sistema, de destruir el tiempo, toda la Historia. El capitalismo expandido, tal como es hoy, parece absorber todas las esferas y, por eso, cualquier posibilidad revolucionaria es absorbida, así como todos los valores son convertidos en moneda, en mercadoría. Según François Hartog (2015), el actual «régimen de historicidad» en que estamos viviendo, conceptualizado en el "presentismo», genera esa percepción de que la lógica catastrófica ya nos es promesa o amenaza, sino la única posibilidad de «futuro». Así, con la catástrofe naturalizada e íntimamente relacionada con la contemporaneidad, lo que existe es un presente expandido, en el cual la dimensión colectiva y la dimensión individual se articulan a fin de proponer posibles modos de sobrevivencias en ese constante presente, visto que el próximo tiempo histórico ya no se configura como tiempo, sino como nada.

Según el brillante artículo de David Jurado de 2016, que hace un análisis sobre los usos y abusos del término catástrofe en el pensamiento latinoamericano, dicho término guarda más relación con las representaciones de los desastres que con la realidad del desastre mismo, ya que su uso depende justamente de las representaciones de mundo, de aquello que para un individuo o grupo, a partir de sus lugares e imaginarios discursivos y culturales, puede ser considerado catastrófico o no. Para el autor, los relatos que representan la catástrofe como un evento que afecta y destruye el tejido social de un grupo de individuos están divididos en tres paradigmas.

El primer paradigma de la catástrofe sería el que ubica el relato después de la catástrofe, después de «la destrucción de una evolución», y la 
catástrofe sería un marco que rompe radicalmente una continuidad. David Jurado llama a este paradigma de catástrofe evento, donde se ubican los relatos más ligados a discursos históricos y mitologías posapocalípticas, que abren un abismo entre el antes y el después de la catástrofe. Muchos relatos en este paradigma se anclan en un presente del pasado, y los personajes se configuran como sobrevivientes o testigos. Pueden vehicular memorias con el proceso de duelo, pero también con un intento de restablecer identidades individuales o colectivas. Muchas de las novelas contemporáneas que trabajan con la catástrofe de la dictadura, como una ruptura del sentido, a partir de una voz ya desolada (y muchas veces residual) por la experiencia disruptiva, estarían ahí ubicadas.

El segundo paradigma pone el relato durante el momento en que la catástrofe irrumpe, y la destrucción adquiere un sentido de continuidad, de catástrofe permanente, sin un tiempo de antes o después. En este sentido, los relatos están en una violencia constante, en el medio de «la evolución de una destrucción», donde el fin, más que inminente, pasa a ser inmanente. En este caso, según el autor, los personajes son los que están en el presente momento del «combate» y los relatos pueden buscar una necesidad de identificar y reconocer las identidades precarias, las comunidades vulnerables que luchan por sus vidas.

Por fin, el tercer paradigma coloca el relato hacia el fin, hacia la destrucción, donde la catástrofe es ilustrada como progresiva y ascendente. Según Jurado, en este tercer sentido, se ubican los relatos en los cuales el fin puede ser representado como providencial o abominable. Aquí estarían los relatos que buscan movilizar ideologías, dibujar estrategias de defensa y de resiliencia, crear identidades colectivas para que el fin, aunque muchas veces dado como cierto, no suceda o no sea tan horrible.

Los días de la peste (2017), la última novela del boliviano Edmundo Paz Soldán, parece formar parte de la tradición del segundo paradigma, la catástrofe permanente, en el cual el relato se construye durante el transcurso de su acontecimiento. Según Juárez Montoya, profesor en la Universidad de Murcia y especialista en la obra de Paz-Sondán,

la zona paz soldaniana expresa el presente, aunque este no se corresponda ya con una determinada imagen de una realidad visual cartesiana asequible a la percepción. El presente que describen las fábulas de Edmundo es un presente terminal. Un presente inasible con forma de futuro que, como sugiere la propia novela, «implosiona» sobre algo extinguido a lo que se le puede llamar presente (Juárez Montoya, 2013).

Inscrito en la generación McOndo, Paz Soldán parece armar un relato que trae muchas soluciones narrativas del realismo mágico dela generación 
de García Márquez, Rulfo, Vargas Llosa y Carpentier; además de una sintaxis que promueve una fragmentación y una proliferación de imágenes espectrales ${ }^{2}$ como en "Casa tomada», de Cortázar, y en La invención de Morel, de Bioy Casares, para imprimir en la novela una realidad que trae a la claustrofobia de la cárcel, una epidemia catastrófica que nadie sabe si proviene de la naturaleza, de un orden divino o del hombre, donde todas las relaciones ya tensionadas por la compleja religiosidad del lugar y las leyes corruptivas que la rigen se vuelven aún más frágiles y hostiles.

En vez de un solo narrador, son más de 30 voces que toman el turno de la palabra, casi todas omniscientes en tercera persona (pero hay también voces en primera de singular y plural), para, a partir de su historia, su experiencia, su lenguaje y personalidad, contarnos la secuencia de días en que se instala una enfermedad mortal y altamente contagiosa en La Casona, una institución carcelaria de grandes proporciones en una región llamada Los Confines. Son presos, agentes penitenciarios, parientes, representantes de la Salud (La doctora Tadic, el Forense, las enfermeras), de la política (el gobernador Lucas Otero, el juez Arandia, el prefecto Vilmos), de la Iglesia (el padre Benítez) y de las fuerzas armadas (el Comandante), etc., que, de dentro o de afuera de La Casona, participan de los juegos de poder que envuelven las más variadas formas de violencia durante esos días.

El montaje que arma la historia de los días de la peste permite que el lector avance de a pocos en la cronología de los sucesos, en vista que, muchas veces en estilo indirecto libre, los relatos regresan y transgreden en el tiempo y espacio, expandiendo el reloj y el escenario, mientras los personajes se presentan y establecen su relación con La Casona. Ya en las primeras páginas, el lector se depara con una enfermedad rara que acomete una bebé, la paciente cero, y también su madre, la paciente uno, que viven dentro de la prisión con el padre y marido, hasta la muerte de ambas. Y al final, después de más de 300 páginas, el cierre se da con La Casona tomada por las Fuerzas Armadas, los presos siendo transferidos a otros lados, pero sin que la peste haya sido controlada: «[El Comandante] al salir se preguntó quién ganaría, si el virus o la Innombrable» (Paz Soldán, 2017, p. 325).

2 «Gente tirada en el primer patio, algunos con uniformes de la policía y otros reclusos, incluso un par de especiales, cerca del palo borracho macizo bajo el cual alguna vez había charlado con su hermano. Unos no daban señales de vida, otros lanzaban ayes lastimeros. Niños y ancianos. Chinelas, laques, trapos, piedras, palos diseminados por el suelo de mosaicos, rodeando la fuente» (Paz Soldán, 2017, p. 313). 
La Casona es una cárcel, pero más parece un barrio laberíntico amurallado, con muchos patios, cuartos de lujos, «carpinterías, quioscos, bares y restaurantes» (p. 34), conexiones a Internet, y consultorios médicos que pueden tener acceso todos los que poseen «tela» o «quivo», es decir, poder adquisitivo. Algunos reos viven allá con sus familias y los niños pueden entrar y salir a la escuela sin ningún problema. Incluso los reos pueden comprar sus días fuera de la cárcel. A veces parece mucho mejor vivir allá dentro que afuera.

Ahora solo buscábamos sobrevivir en un mundo en desacuerdo con nosotros, y no era fácil. Vivíamos con hambre, a base de arroz, tomate y algo de fruta. Hubo que limpiar bajo la mirada severa de una mujer de falda aparatosa. Mientras pulíamos ollas nos olvidamos de dónde estábamos. Era raro todo tan normal. Los clientes debían ser asesinos, violadores, pedófilos, asaltantes, desfalcadores, y ahí los escuchábamos hablar de fútbol y discutir de deudas como si nada (Paz Soldán, 2017, p. 102).

Pero la realidad allá dentro también puede ser muy penosa. La Casona es una estructura («un microcosmos representativo», p. 44) que cumple algunas normas burocráticas y administrativas, pero que hace su propia ley, donde la violencia y la corrupción son sus principales instrumentos de poder. Además, la cantidad de ratas, murciélagos, zancudos y putapariós (unas pulgas), presos locos, agentes penitenciarios con sus chicotes eléctricos pueden hacer de la vida de uno, que ya vale muy poco, un infierno, y aunque la mayoría de las cárceles son diseñadas para que todos estén a la vista, La Casona tiene sectores escondidos, donde casi nadie sabe de la existencia y nadie quiere ir debido a sus «murmullos» y «silbidos», lamentos y llantos, y posibles otras leyes y poderes invisibles que pueden regir estos lugares donde «todo se proliferaba» (p. 217), donde la realidad parece ser demasiado cruda y cruel para permanecer vivo.

Además, están los virus, que durante la novela reciben muchas potencialidades. Por algunos personajes son definidos como monstruos perfectos y seres fantasmales que flotan en el mundo esperando a una célula humana o animal para hacer su estrago. Y por eso no hacen distinción entre un preso, un agente o un gobernador. «Todos eran iguales ante el virus» (p. 307). En la misma década que la Organización Mundial de Salud declara la resistencia antibiótica a las superbacterias y los supervirus como una de las crisis del siglo XXI, la historia de Paz Soldán nos parece muy factible.

Son más inteligentes y no se puede discutir con el saber de milenios. Nosotros quisiéramos ser como ellos. Aspiramos a ser como ellos. Somos un virus, decimos. Pero ellos nos ganan, porque no somos inmunes a los virus. [...] No es que los virus quieran atacarnos. Ni siquiera 
saben que existimos. A ellos les interesa su pequeño mundo que los rodea y nada más. Como a nosotros (Paz Soldán, 2017, p. 234).

La peste es entendida para muchos de los personajes como una respuesta vengativa de Ma Estrella, una deidad de origen indígena, a quienes prácticamente todos en La Casona son devotos y adoradores, también conocida como la Innombrable. En La Casona, la Innombrable tiene su capilla donde los devotos practican sus rituales, rezan y dejan sus ofrendas, y en casi todas las casas hay una imagen de ella: una calavera con un cuchillo entre los dientes. Como el juez ha ordenado al gobernador que se prohibiera el culto dentro de la prisión, muchos pasan a creer que la rara enfermedad que mata en poquísimo tiempo es un castigo de la diosa. La prohibición es un intento de golpe político del juez para que se instale el caos, pero también es la conciencia de que más que el peligro de una nueva religión es el peligro de una nueva cosmovisión, de una nueva episteme, que le da poder al pueblo y lo estimula el deseo de vengarse. Con Ma Estrella, no habría el infierno católico y lo que se hace en esta vida se paga en la misma vida.

No obstante, al mismo tiempo en que muchos remiten a esa plaga una venganza religiosa, el principal personaje representante del área de la Salud, la doctora Tadic, reincide, en varios de sus relatos, que esa no es ni la primera ni la segunda vez que una enfermedad de grandes proporciones se estalla en La Casona, sino que es algo que sucede de tiempos en tiempos en la cárcel. «No le sorprendía [a la doctora] que el miedo cundiera y que entre los presos no se hablara más de la plaga. Debía tomarlo con calma, responder a las preguntas que le hicieran, darles la información de la que disponía. Ya había vivido esto y sin duda volvería a vivir en el futuro» (Paz Soldán, 2017, p. 233).

Jean-Luc Nancy (2014) afirma, en su obra La equivalencia de las catástrofes, cuando trata del terremoto que devastó la zona nuclear de Fukushima en 2011, que en el Estado neoliberal en que estamos todos en el siglo $X X I$, ya no hay diferenciación entre las catástrofes naturales y las causadas por los humanos ${ }^{3}$. Lo que hay es una catástrofe civilizatoria que se propaga siempre que hay un desastre, por descaso del Estado. Como afirma

3 Podemos pensar en otros eventos: el no aviso a las poblaciones costeras de Chile sobre el terremoto que ya sabía la marina costera chilena y que costó la vida de más de 500 personas, la no actuación del Estado estadunidense en Nueva Orleans tras el huracán Katrina en 2005, la ola de calor que mató a 50000 personas en Rusia en 2010, o los incendios de Portugal y de la Amazonía. Pero lo que hace que Fukushima sea aún más catastrófico es que no hubo solo una destrucción, causada por un accidente natural y un accidente técnico, sino que hubo una antirreconstrucción, es decir, una anulación de una habitabilidad, de un espacio y de un tiempo después de la catástrofe. 
también Boaventura de Sousa Santos, la catástrofe es solamente una de las estrategias del Estado neoliberal para que el propio Estado 4 pueda intervenir radicalmente en determinadas comunidades o áreas, con el discurso de reintegrar la seguridad y la salud, y reinstaurar la normalidad para una población. Como dice Krupa, uno de los agentes penitenciarios de La Casona, esa estrategia de dejar a que se mueran, es «Una forma necesaria de vaciar las celdas de tanto en tanto, de impedir el rebalse» (Paz Soldán, 2017, p. 172).

La lenta burocracia mencionada en una conversa del forense con la doctora (p. 180), que es de praxis cumplir en toda situación atípica que envuelve la Salud, parece que es un más de esos procedimientos-impedimentos para que no se controle la peste, una estrategia propia de la política para seguir con el control poblacional, y que también sirve como herramienta para acentuar el abismo entre los que tienen poder y la sociedad civil incivil, sujeta a cualquier tipo de fascismo social a partir de criterios de exclusión: raciales, etarios, geográficos, de clase, de diferencia sexual, etc.

Para los que están salvos, o sea, los que están del lado seguro del abismo, la catástrofe no llega a ser considerada una catástrofe, sino meramente una «situación conflictiva» (p. 203). Pero para los que no están a salvos, dice 43, un preso que ni siquiera tiene nombre: «La cárcel era la cárcel era la cárcel» (p. 65). Es decir, no hay solución, porque no hay modo de salir de la cárcel. Y no porque no haya forma de escapar de La Casona, sino porque el carcelario es la condición de que no hay escapatoria. Es el estatuto identitario que el sistema bautizó y ahí lo mantiene. Ahí está la verdadera catástrofe para Jean-Luc Nancy: la equivalencia generalizada y homogeneizante de la vida (que es imposible de valorar) y las cosas. Para el Estado actual, todo es un coste.

Propone el doctor Achebi: «Cerrar La Casona. [...] Trasladar a todos a una nueva prisión, construida para resolver el problema. Esa prisión se llamará La Casona» (p. 284). O sea, mientras no haya la catástrofe definitiva o alguna forma de insurrección estructural, los sin derechos estarán así condenados en un eterno looping. Todos los que viven y trabajan en La Casona son los excluidos, y aunque parezcan tener diferentes niveles de «libertad», de «poder», están todos aprisionados en una catástrofe dentro de otra catástrofe. La mención a la condición igualitaria de precariedad de

4 Boaventura de Sousa Santos (2009) propone una tipología de cinco discursos de producción de una alteridad radical en los «espacios coloniales y neocoloniales» utilizadas por el Estado para lógicas específicas de intervención: la tropicalidad, el desarrollo, la producción de drogas ilegales, el terrorismo y la que vemos representada en la novela de Paz Soldán, los desastres. 
todos incluso es repetida innúmeras veces en la novela y por distintas voces: «Usted es igual que yo y apenas sale. Somos todos iguales, dijo Krupa» (p. 170)»; «Todos somos hermanos, pero con diferentes disfraces» (p. 303), «Es lo mismo, doctora, ser preso que ser guardias, es lo mismo. Algunos de ellos ganan más que nosotros y tienen mejores casas» (p. 283).

Y por vivir en una catástrofe permanente, muchas son las estrategias utilizadas por los personajes para sobrevivir. Casi todas tienen que ver con modos de salir de sí, de formas muy distintas. Tiralíneas, por ejemplo, uno de los presos, intenta hacerse de muerto (p. 308); Celeste, la mujer del gobernador, participa de ceremonias de Ma Estrella con sustancias alucinógenas que le permite pasar horas en trance; Tullido quiere implantarse una prótesis de pierna biónica para tornarse un hombre-cyborg; Hinojosa consume porno compulsivamente; y la mayoría de los presos consume tonchi, pastillas lisérgicas u otras drogas. Los modos de salir de sí para poder sobrevivir incluso acaban tornándose mercadoría a ser negociada, visto que el propio sistema encuentra su manera de beneficiarse con la amenaza de una gran catástrofe.

En las paredes anuncios de astrólogos que ofrecían leer «preferentemente de noche», si la plaga estaba mencionada en las estrellas de quien consultaba su futuro, y de médicos aparecidos de improviso, vendiendo ungüentos y curas extravagantes, ofreciendo su experiencia («ivencí la plaga del Norte, sé cómo tratarte!»), usando su celda o cuarto como si tratara de un consultorio. Había quienes preferían no salir al aire libre, pero a otros los tentaba el bisnes y ofrecían trajes protectores de confección casera («no sirven de nada», dijo la doctora), comidas limpias de toda contaminación, veneno de sapo para desintoxicaciones («no son lo que yo quiero», se molestó Lillo cuando se lo llevaron a su departamento). Se vendían termómetros, barbijos, medicamentos antipalúdicos [...]. Quienes se autoaislaban habían aprendido a hacerlo en sus pueblos azotados por plagas, pero otros preferían pensar que la protección de la [diosa] Innombrable era suficiente para preservarlos (Paz Soldán, 2017, p. 236).

Además de todas esas «salidas», Paz Soldán también nos propone otras dos estrategias de sobrevivencia que nos parece que vale la pena profundizar. Una de ellas nos es presentada en la figura del Loco de las Bolsas, un preso que disuelve su yo, hasta tornarse una especie de coro del teatro griego, que representa a todos y es nadie, la propia máquina de Morel, una saturación de imágenes ajenas, citas de múltiples voces: del discurso religioso, de letras de música, de gritos de otros presos, de muletillas de presentadores de la televisión, de la radio y otras referencias. Con nuestras identidades individuales (y también colectivas) bajo presión, la simultaneidad de tradiciones, de hipertextos fragmentados, configura 
la forma quizás más contemporánea de salir de sí, de perder su identidad y quizás sobrevivir. Además, cuando él cubre su rostro, manos y pies con bolsas de plástico también niega su cuerpo. Ni sujeto ni individuo. En un intento de garantizar su existencia, se vuelve imagen.

Quién hace tanta bulla y no respeta la paz que va quedando. Un poco de consideración por favor. Es solo el silencio el que te llama, cansado ante la tarde gris de angustia. No te pongas triste de saberte solo, sal pronto a la calle, vístete temprano, La Casona está llena de voces y pasos, y tú estás solo en un mundo de metal. Disparos, disparos. ¿De quién es este cuchillo? ¿Quién lo ha tirado aquí? ¿Para mí, para mí? El reposo caliente aún de ser. Gran circo gran señores, con la famosa cabra hipnotizadora. Y ahora. Con una coima los dejaré salir. Ma Estrella es mi señora, nada me faltará. Abran su corazón, señores, no es una raza maldita, ellos no tienen la culpa. Los microbios hacen lo que pueden. (Paz Soldán, 2017, p. 304).

Otra estrategia de sobrevivencia es la que es desarrollada en el personaje Rigo, uno de los personajes más bien construidos de la novela, a quien Vicente Luis Mora (2017) lo define como un yo asambleario, "consciente de su dimensión sociopolítica en escala». Dice Rigo: «Aprendíamos a disolver el yo en el nosotros, el yo era un pueblo y debíamos cuidarlo» (p. 36). Rigo es un preso que, al principio, parece no entender la razón por la cual está encarcelado, ni tampoco entiende cómo se estructura socialmente la cárcel adonde fue llevado. Él incluso dice que, excepto por los muros que separan de la ciudad y las torres de vigilancia, se parece realmente a una ciudad. Con el pasar de los días, Rigo intenta adaptarse al nuevo escenario, buscando encontrar su «misión». Por tener una religión que todos los seres vivos tienen la misma importancia, llamada de «Transfiguración», Rigo no mata a los insectos ni tampoco come carne. También por eso, sus relatos están siempre en la primera persona del plural, ya que considera que él mismo es un compuesto de innúmeros virus, bacterias y otros seres. Incluso sus miembros, brazos y piernas son repartidos y considerados seres singulares, capaces de tener sus propios temores y deseos. Esa fórmula micropolítica de resistencia, de yo-múltiple, Roberto Espósito (2017) llama de «singularidad impersonal» o «impersonalidad singular», que, según el autor, rompe con las formas de individuación de los hombres, plantas, animales, etc., a favor de una biopolítica afirmativa, de un devenir más allá de un yo, que permite preocuparse por lo que viene después del sujeto e por eso incluso vincularse al concepto de poshumano, que resiste a quedarse en la cápsula de una identidad y busca una solución de sí para todos y de todos para sí. 
Como afirma Isabelle Stengers, en «No tempo das catástrofes», el carácter intrínsecamente insostenible del desarrollo del sistema capitalista tal como es ahora ya es un saber común. Los problemas se acumulan y, aunque muy pocos sean los dueños de los bienes de producción y tienen el real poder de decisión, tendremos que no solo seguir exigiéndoles el protagonismo que les cabe ${ }^{5}$, sino también asumir nosotros lo que ya sabemos y cumplir nuestra obligación delante del actual panorama.

El saber, que hoy es común, nos obliga a tener presencia, dice Stengers, juntos, uno por el otro y uno con el otro. Si hay algo que la novela de Paz Soldán nos muestra es que hay muchos Otros. Y aunque sean representantes del Estado, de la Iglesia, de la Salud, agentes mantenedores del orden, presos políticos, ladrones de esquina, niños inocentes, mientras cada uno busque su forma de sobrevivir de forma singular, es decir, de inmunizarse como individuo, no habrá comunidad, no habrá futuro. Pero Paz Soldán no cierra su novela, es decir, no revela un ganador, mucho menos revela si habrá realmente un ganador. Lo que nos queda de Los días de la peste es una pregunta: ¿cuál es la salida que lleva en cuenta a todos?

[La doctora] comprendía que la necedad del virus no era nada ante el barullo desorbitado de los humanos. El virus era lo que era, no tenía opciones. Los humanos en cambio se esmeraban en el desmadre cuando asomaba el peligro, en la búsqueda de salidas que no tuvieran en cuenta a todos, en la piedad hueca, tanta religión no servía de mucho (Paz Soldán, 2017, p. 307).

No hay tiempo futuro, pero eso no significa que haya la pérdida del tiempo. Si no hay tiempo futuro, también será el presente el tiempo que sobreviene, que se presenta, que debe configurarse como un lugar de resistencia, donde las voces no son silenciadas. Es el proprio presente el tiempo que abarca todo. El presente como el tiempo simultáneo de Borges en el jardín de los senderos que se bifurcan. Si la catástrofe, según el sociólogo argentino Gabriel Gatti, supone «el desajuste permanente entre las palabras y las cosas», lo que hace Paz Soldán en su novela, aunque estén sus personajes delante del encierro y de la intemperie, es explorar nuevas formas de lenguaje, reinventando sentidos ${ }^{6}$ que les permitan desarrollar nuevas formas de hacer política, otras potencias éticas de vivir, otras formas de comunidad. Que sigamos entonces el diálogo.

5 Aunque sabemos también que ellos no tienen ningún interés de cambiar las leyes de mercado o disminuir el lucro de sus empresas, ni mucho menos que haya reglamentación, fiscalización y medidas en contra los «excesos».

6 En cursivas por ser palabras referidas al texto de Jean-Luc Nancy (2014). 


\section{Contribuciones}

Ellen Maria Martins de Vasconcellos ha participado en la concepción del artículo, en la recolección de datos, en la redacción y aprobación de la versión final.

\section{Fuente de financiamiento}

Autofinanciado.

\section{Conflictos de interés}

La autora declara no tener conflicto de interés.

\section{REFERENCIAS BIBLIOGRÁFICAS}

Camacho, J. M. (2019). Horrores globales. Religiosidad popular, mundo carcelario y pandemia en Los días de la peste de Edmundo Paz Soldán. In Eva Valero Juan y Oswaldo Estrada (Eds.). Literatura y globalización. Latinoamérica en el nuevo milenio (pp. 141-152). Barcelona: Anthropos.

Espósito, R. (2017). Termos da política: comunidade, imunidade, biopolítica. Paraná: Universidade Federal do Paraná.

Garramuño, F. (2018). Potencias de la vida anónima. Trabajo presentado en el congreso «Heroes and the people», organizado por Swiss School of Latin American Studies, en Suiza. Recuperado de https://www.academia. edu/36864508/Potencias_de_la_vida_an\%C3\%B3nima

Jorza, D. (2012). La figuración de una utopía política en El delirio de Turing de Edmundo Paz Soldán. Revista Hispánica Moderna, 65(1), pp. 47-64. Recuperado de https://www.academia.edu/9118626/_La_figuración_de_ una_utop\%C3\%ADa_pol\%C3\%ADtica_en_El_delirio_de_Turing_de_Edmundo_Paz_Soldán_._Revista_Hispánica_Moderna_65.1_June_2012_

Montoya Juárez, J. (2013). Tecno-ficción boliviana: imagen y tecnología en la obra de Edmundo Paz Soldán. Dissidences, 5(9). Recuperado de https:// digitalcommons.bowdoin.edu/dissidences/vol5/iss9/4

Montoya Juárez, J. (2019). La velocidad de los cuerpos: mercado, distopía y desecho en Los días de la peste, de Edmundo Paz Soldán. Co-herencia, 16(30), pp. 159-187. Recuperado de http://publicaciones.eafit.edu.co/index.php/co-herencia/article/view/5305/4386 
Jurado, D. (2017). Uso y abusos del término «catástrofe» y de sus narrativas en el pensamiento latinoamericano. Recuperado de https://catnotes. hypotheses.org/634

Mendes, J. (2016). A dignidade das pertenças e os limites do neoliberalismo: catástrofes, capitalismo, Estado e vítimas. Sociologias. Porto Alegre, 18(43), pp. 58-86.

Mora, V. L. (2017). El yo asambleario de Los días de la peste. Recuperado de http://vicenteluismora.blogspot.com/2017/08/el-yo-asambleario-de-losdias-de-la.html

Nancy, J. L. (2014). Equivalencia das catástrofes. Lisboa: Nada.

Placard Cultural (s. f.). El momento cero de Los días de la peste, la última novela de Edmundo Paz-Soldán. Recuperado de http://placardcultural. com/index.php/el-momento-cero-en-la-carcel-de-edmundo-paz-soldan/ Paz Soldán, E. (2017). Los días de la peste. Barcelona: Malpaso.

Stengers, I. (2015). No tempo das catástrofes. São Paulo: Cosac Naify.

Recibido: 24/9/2019

Aceptado: 5/11/2019 